\title{
O PARFOR NA UNIVERSIDADE FEDERAL DO OESTE DO PARÁ (UFOPA): PERSPECTIVAS PARA A MELHORIA NA PRÁXIS PEDAGÓGICA
}

\author{
Eliane Gracy Lemos Barreto ${ }^{1}$ \\ Anselmo Alencar Colares ${ }^{2}$
}

\begin{abstract}
RESUMO
O presente artigo tem como objetivo analisar o processo de implementação e os resultados do PARFOR na UFOPA (Campus Monte Alegre/PA), no período de 2010-2014. Parte do princípio de que as políticas de formação docente, implementadas no Brasil, nas últimas décadas, têm conseguido atender os aspectos quantitativos diante da demanda por capacitação profissional, no entanto, faz-se necessário atender os aspectos qualitativos dessa formação, pois o conhecimento teórico docente é importante, mas este não deve se sobrepor à capacitação didático-pedagógica necessária à práxis docente. A metodologia utilizada baseou-se na abordagem qualitativa, a partir de pesquisas bibliográfica, documental e de campo, com a utilização de entrevistas e questionários semiestruturados, alicerçados em três categorias de análises. Os resultados apontam que, para que haja significativa mudança na ação didático-pedagógica, tornam-se imprescindíveis adequações nos processos de implementação e de gestão dessa política. Há problemas, contudo há também enormes possibilidades de que os resultados do PARFOR não sejam apenas quantitativos, mas reflitam efetivamente na melhoria da práxis pedagógica docente.
\end{abstract}

Palavras-chave: PARFOR; UFOPA; Formação inicial e continuada; Capacitação didáticopedagógica.

\section{PARFOR (TEACHER TRAINING PROGRAM) AT THE FEDERAL UNIVERSITY OF PARÁ WEST (UFOPA): PERSPECTIVE FOR IMPROVING THE EDUCATIONAL PRAXIS}

\begin{abstract}
This article aims to analyze the implementation process and the results of PARFOR at UFOPA (Campus Monte Alegre/PA) in the period of 2010-2014. Teacher education policies implemented in Brazil in recent decades have been able to meet the quantitative aspects on the demand for professional training, however, it is necessary to meet the qualitative aspects of such training because teaching theoretical knowledge is important, but this should not overlap the didactic and pedagogical training necessary for teaching practice. The methodology was based on qualitative approach from bibliographical research, documentary and research field, using the semi-structured interviews and questionnaires based in three categories of analysis. Considering the significant change in the didactic and pedagogical action, the results revealed that is necessary adjustments in the implementation processes and management of this policy. There are problems, but there are enormous possibilities considering the results of PARFOR reflect effectively the improvement of the teaching pedagogical praxis, going beyond the quantitative results.
\end{abstract}

Keywords: PARFOR; UFOPA; initial and continuing training; didactic and pedagogical training. 


\section{Introdução}

Após a redemocratização do ensino e a promulgação da Lei de Diretrizes e Base da Educação Nacional - Lei n. ${ }^{\circ}$ 9.394/1996 (LDB), o professor tem sido alvo de debates com vistas à sua qualificação profissional, entendida pelos formuladores de políticas públicas como importante e necessária para a melhoria do processo ensino-aprendizagem. Diante da implementação de políticas públicas referentes à formação de professores que atuam na educação básica pública no Brasil, um número significativo de profissionais tem sido contemplado. No entanto, seus resultados não têm causado mudanças significativas ante aos problemas relacionados à falta de qualidade no ensino. A literatura revela um consenso entre vários estudiosos ${ }^{3}$ sobre a temática "Políticas Educacionais e Formação Docente" no que diz respeito às políticas públicas voltadas para formação/qualificação de professores concebidas nas últimas décadas do século XX e ainda em desenvolvimento no século XXI - não têm sido suficientes para responder positivamente diante dos problemas relacionados ao ensino público brasileiro. Pois esses problemas não estão condicionados apenas à falta de formação e/ou à formação adequada dos docentes em exercício. Diversos fatores, como por exemplo, a forma de implementação e gestão no processo de implantação dessas políticas podem interferir nos resultados alcançados.

Desta forma, este trabalho teve como objetivo analisar o processo de implementação e os resultados do PARFOR na UFOPA (Campus Monte Alegre/PA), no período de 2010-2014. Os sujeitos delimitados para o estudo foram: 1) a Coordenadora Geral do PARFOR na UFOPA; 2) o Coordenador Local do PARFOR no município de Monte Alegre e; 3) o Secretário de Educação deste Município que, por determinação legal deste Plano deverá participar efetivamente do processo de implementação do PARFOR em parceria com o gestor municipal. Todos os entrevistados assinaram um Termo de Consentimento Livre e Esclarecido, por meio do qual informamos que o uso das informações estaria submetido à ética e ao rigor acadêmico-profissional.

Por intermédio da UFOPA o PARFOR possui 07 (sete) polos de funcionamento na Região Oeste Paraense em diferentes municípios ${ }^{4}$. Porém, delimitamos o município de Monte Alegre para a realização desta pesquisa, devido ter sido o polo que atendeu e formou o maior número de professores-alunos no período de 2010-2014, recorte histórico desta pesquisa.

A metodologia utilizada baseou-se na abordagem qualitativa a partir de pesquisas bibliográfica, documental e de campo, com a utilização de entrevistas e questionários semiestruturados, alicerçados em três categorias de análises: 1) Gestão; 2) Implementação e; 3) Resultados.

A análise nos revelou particularidades no processo de implementação deste Plano na UFOPA, limites e possibilidades, sucessos e fragilidades, assim como a área de abrangência e o percentual elevado de docentes formados/capacitados por este plano. Compreendemos que o quantitativo de professores contemplados não representa garantia de qualidade no ensino público, uma vez que o mesmo apresenta algumas fragilidades no que diz respeito ao seu processo de gestão e implementação. No entanto, percebemos enormes possibilidades, para que os resultados do PARFOR não sejam apenas em termos quantitativos, mas reflitam efetivamente na melhoria da práxis pedagógica docente. 


\section{O Plano Nacional de Formação dos Professores da Educação Básica (PARFOR): Princípios, objetivos e metas}

O Plano Nacional de Formação dos Professores da Educação Básica (PARFOR) surgiu em um contexto em que a necessidade de formação docente era evidente em toda a conjuntura nacional, apresentando como objetivo principal, promover formação inicial e continuada aos professores em exercício, sem formação adequada, atuantes na educação básica pública estadual e municipal.

Pois, se anteriormente a qualificação mínima necessária para o exercício da docência na educação infantil e nas quatro primeiras séries do ensino fundamental era apenas o ensino médio completo na modalidade Normal, a partir da promulgação da LDB - Lei n. ${ }^{\circ}$ 9.394/96, passou a ser exigida a formação em nível superior.

Entretanto, diante do contingente de professores que necessitavam dessa formação e da inexistência de agências formadoras capazes de suprir as necessidades de forma suficiente, essa mesma Lei admitiu que tal formação ainda se mantivesse em nível médio, porém, no máximo até dezembro do ano de 2006.

A partir da década de 1990, a legislação nacional, por meio de decretos e leis de incentivo e apoio à formação inicial e continuada de professores, como é o caso da LDB n. ${ }^{\circ}$ 9.394/96, implementou inúmeras políticas públicas para a formação docente, as quais priorizavam o acesso a níveis superiores através de programas de formação inicial e de aperfeiçoamento, tanto em instituições de ensino superior de natureza pública, quanto de natureza privada, ofertados na modalidade presencial e à distância.

Deste modo, a Política Nacional de Formação dos Profissionais do Magistério para Educação Básica foi instituída pelo Decreto n. ${ }^{\circ}$ 6.755, de 29 de Janeiro de 2009, e posteriormente, o Plano Nacional de Formação dos Professores da Educação Básica (PARFOR) foi instituído por meio da Portaria Normativa n. ${ }^{\circ}$ 9, de 30 de Junho de 2009.

Evidenciamos, portanto, que este Programa foi implantado em regime de colaboração entre a Coordenação de Aperfeiçoamento de Pessoal de Nível Superior (CAPES), os estados, os municípios, o Distrito Federal e as Instituições de Ensino Superior (IES); com o objetivo principal de garantir que os professores em exercício na rede pública de educação básica obtivessem a formação exigida pela Lei n. ${ }^{\circ}$ 9.394/96 (LDB), visando ainda induzir e fomentar a oferta de educação superior, gratuita e de qualidade, na intenção de que a partir dessa formação esses profissionais pudessem contribuir para a melhoria da qualidade da educação básica pública no país.

Diante da implementação deste Plano, de acordo com seu Manual Operativo, o mesmo visa à composição de turmas especiais, com a participação efetiva das IES, em cursos de: 1) Primeira Licenciatura para docentes ou tradutores intérpretes da Língua Brasileira de Sinais (LIBRAS), em exercício na rede pública da educação básica, que não tenham formação superior ou que mesmo tendo essa formação se disponham a realizar curso de licenciatura na etapa/disciplina em que está atuando em sala de aula; 2) Turmas de Segunda Licenciatura, destinadas a professores que estejam em exercício há pelo menos três anos na rede pública de educação básica e que atuam em área distinta da sua formação inicial, ou a profissionais que atuam como tradutor intérprete de Libras; e 3) A Formação Pedagógica. Esta terceira composição de turmas tem como objetivo formar docentes graduados não licenciados que se encontram no exercício da docência ou que atuam como tradutor intérprete de Libras na rede pública da educação básica.

O Decreto estabelecido por este Plano, em seu artigo $2^{\circ}$, inciso I, institui: "A formação docente para todas as etapas da educação básica [...], buscando assegurar o 
direito das crianças, jovens e adultos à educação de qualidade". E ainda no artigo $3^{\circ}$, inciso I, estabelece o objetivo de: "promover a melhoria da qualidade da educação básica pública". Cabendo a CAPES, através do Fundo Nacional de Desenvolvimento da Educação - FNDE, o financiamento deste Plano e a operacionalização do processo através da Plataforma Freire ${ }^{5}$, disponível no endereço eletrônico https:/freire.mec.gov.br, na qual os professores se inscrevem, tendo como parâmetros os dados do Educacenso $^{6}$ e a validação realizada pelas Secretarias Estaduais e Municipais de Educação.

Em suma, a análise desse Plano de formação docente baseou-se na leitura da legislação básica vigente ${ }^{7}$ que o compõe e da pesquisa de campo realizada na UFOPA, a partir das quais buscamos compreender o seu processo de gestão e implementação. Esses dados nos permitiram melhor compreensão dessa Política de formação docente, assim como o entendimento de seus objetivos e metas.

\section{O PARFOR na Universidade Federal do Oeste do Pará - UFOPA}

Percebemos que esta política educacional voltada para a formação de professores em exercício na educação básica, apresenta mecanismos de implementação, objetivos e metas em sua regulamentação. No entanto, entendemos que a elaboração de uma política não se conclui no ato de sua formulação e precisa ser avaliada ao longo de todo o seu processo de implementação, que dependerá do local, dos atores envolvidos, do nível de envolvimento e conhecimento de cada um e, ainda, das circunstâncias encontradas durante sua execução.

Dessa forma, objetivamos compreender: Como se deu o processo de implementação do PARFOR na UFOPA? Qual o modelo de gestão adotado para sua implementação? e Quais os resultados alcançados?

A UFOPA foi criada pela Lei $\mathrm{n}^{\circ} 12.085$, de 5 de novembro de 2009, é situada em um dos pontos estratégicos da Amazônia, o município de Santarém, a terceira maior cidade paraense, e desenvolve suas atividades em três unidades, localizadas em diferentes bairros: Unidade Rondon, Unidade Tapajós e Unidade Amazônia. Originou-se a partir da incorporação do Campus de Santarém da Universidade Federal do Pará (UFPA) e da Unidade Descentralizada Tapajós da Universidade Federal Rural da Amazônia (UFRA), ambas com atividades na região oeste paraense e responsáveis por outras unidades situadas nos municípios de Alenquer, Itaituba, Juruti, Monte Alegre, Óbidos e Oriximiná.

Sua criação faz parte do programa de expansão das universidades federais, fruto de um Acordo de Cooperação Técnica firmado entre o Ministério da Educação (MEC) e a Universidade Federal do Pará (UFPA), o qual objetivou ampliar o ensino superior na região amazônica.

A partir da promulgação dessa Lei, os cargos ocupados e vagos do Quadro de Pessoal da UFPA, foram redistribuídos para a UFOPA para o funcionamento do campus de Santarém e dos Núcleos em Itaituba e Oriximiná e da Unidade Descentralizada da UFRA/Tapajós. Composta na data de publicação desta Lei, por 432 (quatrocentos e trinta e dois) cargos efetivos de professor da carreira de magistério superior; 120 (cento e vinte) cargos efetivos técnico-administrativos de nível superior e 212 (duzentos e doze) cargos efetivos técnico-administrativo de nível médio.

De acordo com o Diário Oficial da União no 130, de 9 de Julho de 2010, através do processo $n^{\circ}$ 23038.004959/2010-72, a CAPES formalizou a adesão da UFOPA ao Acordo de Cooperação Técnica com vistas à implantação do Plano Nacional de Formação dos Professores da Educação Básica (PARFOR), o qual foi instituído pelo MEC, destinado a 
atender a demanda de professores das redes públicas estadual e municipal, com vigência de 07 (sete) anos, a partir de sua data de assinatura, ocorrida em 25 de junho de 2010. Dessa forma, percebemos que logo após a criação da UFOPA, ou seja, 8 (oito) meses após sua criação, o PARFOR é implantado e implementado nesta Universidade.

A primeira etapa de funcionamento do PARFOR na UFOPA foi garantida a partir da assinatura do Termo de Cooperação Simplificado, firmado em 15 de julho de 2010, com verbas destinadas ao deslocamento dos professores, visando ao pagamento de diárias e passagens.

Em 23 de novembro desse mesmo ano, um novo Termo de Cooperação Aditivo é assinado, visando a oferecer suporte didático para sistematizar melhor os conteúdos trabalhados em sala de aula e para manter a limpeza e higienização das escolas onde os cursos do PARFOR funcionam no Estado do Pará.

Em 15 de julho de 2011, mais um Termo Aditivo de Cooperação é assinado entre a CAPES e a UFOPA, com vigência prevista para 31 de dezembro de 2014, com a destinação de recursos às turmas já iniciadas e às novas turmas a serem implantadas ao longo de quatro anos, compreendidos entre os anos de 2011-2014.

No ano de 2014, a equipe de coordenação do PARFOR na UFOPA era composta por uma Coordenadora Geral Institucional do PARFOR/UFOPA, um Coordenador Geral Adjunto e um Gestor Administrativo Institucional.

Diante da área de abrangência deste Plano, até o mês de outubro do ano de 2014, a UFOPA, através do PARFOR, contemplou um número significativo de professores/alunos, conforme demonstra a Tabela 01.

Tabela 01. Quantitativo total de alunos ativos do PARFOR/UFOPA, por turma, por curso e por município.

\begin{tabular}{|c|c|c|c|c|c|c|c|c|c|c|c|c|c|c|c|c|c|c|c|c|c|c|c|c|c|c|c|}
\hline \multirow[b]{2}{*}{ Município } & \multicolumn{4}{|c|}{ Biologia e Química } & \multicolumn{5}{|c|}{ História e Geografia } & \multicolumn{6}{|c|}{ Português e Inglês } & \multicolumn{5}{|c|}{ Matemática e Física } & \multicolumn{6}{|c|}{ Pedagogia } & \multirow{2}{*}{ : } \\
\hline & $\stackrel{\text { సิ }}{\bar{i}}$ & $\overline{\overline{\mathrm{N}}}$ & $\widetilde{\bar{ิ}}$ & $\stackrel{m}{\tilde{\pi}}$ & 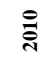 & $\overline{\overline{\widehat{N}}}$ & ิㅗำ & $\stackrel{m}{\bar{乛}}$ & ֻั) & 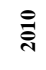 & $\overline{\bar{ิ}}$ & ิㅗำ & $\begin{array}{l}\underset{\mathbf{I}}{\mathrm{N}} \\
\stackrel{\mathrm{N}}{2}\end{array}$ & $\stackrel{\tilde{\Xi}}{\pi}$ & ָे & $\stackrel{ }{\bar{\sim}}$ & $\overline{\bar{\Xi}}$ & ิㅗㄱ & $\stackrel{m}{\bar{\pi}}$ & $\stackrel{\widetilde{m}}{\tilde{\pi}}$ & 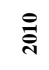 & $\overline{\overline{\mathrm{N}}}$ & בְ. & ิㅗㄱ & $\stackrel{m}{\bar{N}}$ & लำ & \\
\hline Alenquer & 34 & 31 & 40 & & 37 & 45 & 30 & & & 38 & 31 & 36 & & & & 36 & 30 & 18 & & & 36 & 44 & 33 & 37 & & & 556 \\
\hline Almeirim & 16 & & & & 26 & & & & & 45 & & & & & & 25 & & & 14 & & 46 & & & & 27 & & 199 \\
\hline Itaituba & & & 29 & & 21 & & 27 & & & 23 & 13 & 34 & & 25 & & 15 & 22 & 20 & 17 & & 31 & 30 & & & 30 & & 337 \\
\hline Juruti & 28 & & & & 38 & & & & & 41 & & 27 & & & & 34 & & & & & 45 & 21 & & 30 & 27 & & 291 \\
\hline $\begin{array}{l}\text { Monte } \\
\text { Alegre }\end{array}$ & 35 & & & & 39 & & 26 & & & 35 & & 26 & & & & 44 & & & 22 & & 39 & 22 & & & & & 288 \\
\hline Oriximiná & 16 & & & & 36 & & 26 & & & 42 & 32 & 23 & & & & 25 & & 23 & & & 47 & 41 & & 24 & 25 & & 360 \\
\hline Óbidos & 23 & 15 & & & 41 & 37 & 20 & & & 39 & 35 & & & & & 49 & & 22 & & & 47 & 43 & & 33 & 28 & & 432 \\
\hline Santarém & 22 & 15 & 20 & 38 & 33 & 31 & 33 & 33 & 33 & 38 & 34 & 35 & 34 & 41 & 42 & 37 & 21 & 36 & 22 & 24 & 35 & 28 & & 31 & 45 & 37 & 798 \\
\hline TOTAL & 174 & 61 & 89 & 38 & 271 & 113 & 162 & 33 & 33 & 301 & 145 & 181 & 34 & 66 & 42 & 265 & 73 & 119 & 75 & 24 & 326 & 229 & 33 & 155 & 182 & 37 & 3261 \\
\hline
\end{tabular}

Fonte: Secretaria da Coordenação Geral Institucional do PARFOR na UFOPA. Atualizado em outubro de 2014.

A partir da Tabela 01, percebemos que até este período o PARFOR, através da UFOPA, esteve presente em 08 (oito) municípios no Oeste do Pará: Alenquer, Almeirim, Itaituba, Juruti, Monte Alegre, Oriximiná, Óbidos e Santarém. Com a implantação de 26 turmas, 3.261 professores-alunos ativos até outubro deste ano. Ofertando cursos em 05 (cinco) áreas distintas, quatro organizados como Licenciaturas integradas (1. Biologia e 
Química; 2. História e Geografia; 3. Português e Inglês; 4. Matemática e Física) e o curso de Pedagogia.

De acordo com os dados oficiais do PARFOR/UFOPA, os profissionais contemplados e formados por este plano, os quais iniciaram sua formação no ano de 2010 , através da UFOPA e que já concluíram sua formação no ano de 2015, somam um total de 914 professores na região oeste paraense.

\section{O PARFOR/UFOPA no município de Monte Alegre: Limites e possibilidades para a formação docente}

Neste tópico destacamos as vozes dos coordenadores do PARFOR nos municípios de Santarém e Monte Alegre e do Secretário Municipal de Educação do município de Monte Alegre atuantes no período da pesquisa (2010-2014).

A análise objetivou compreender os processos de gestão e implementação do PARFOR, assim como os resultados alcançados através da UFOPA nesse município. As interpretações/inferências se concentraram na regulamentação deste Plano a partir dos documentos que o legalizam, em estudos realizados anteriormente sobre esta política e nas concepções e percepções desses sujeitos a partir de três categorias de análise, definidas neste estudo: 1) Gestão; 2) Implementação e; 3) Resultados.

\subsection{Práticas de Gestão do PARFOR na UFOPA}

A partir das leituras realizadas para este estudo, compreendemos que diante da análise de qualquer política pública, a gestão é caracterizada como o ponto culminante para a sua execução e precisa estar alicerçada em princípios norteadores que farão com que este processo ocorra de forma compartilhada e atinja os objetivos propostos. Dessa forma, a transparência e a autonomia, tornam-se princípios relevantes para o sucesso deste processo.

Assim, objetivamos analisar as práticas de gestão do PARFOR na UFOPA (Campus de Santarém e Monte Alegre) no que diz respeito à atuação dos Coordenadores (Geral e Local) e à relação desenvolvida entre os mesmos e a gestão municipal, pois os coordenadores são responsáveis por promover a integração das atividades nos diferentes segmentos.

As entrevistas realizadas com os coordenadores e com o secretário municipal de educação foram relevantes para compararmos a gestão desenvolvida por esta Universidade com a gestão regulamentada pelo Manual Operativo do Plano, assim como para observarmos as particularidades, singularidades e dificuldades enfrentadas por cada um no processo de gerenciamento e implementação do PARFOR nessa Universidade.

Constatamos que, desde sua implantação na UFOPA, o PARFOR já contou com 06 (seis) coordenações, sendo uma delas atuantes em dois períodos distintos. No entanto, este fato, segundo relatos da coordenação atual, não se deve à falta de competência dos coordenadores, o mesmo tem a ver com questões relacionadas à mudança de reitoria e ao fato de alguns coordenadores terem que sair do município em busca de qualificação profissional em outros estados e/ou municípios, ou precisarem assumir outros cargos dentro da universidade; algumas mudanças estavam relacionadas às precárias condições do quadro de funcionários desta Universidade.

Dessa forma, fica evidente que as questões relativas às mudanças de coordenadores e demais sujeitos que compõem a equipe gestora estão intimamente ligadas às questões 
políticas e essas dificuldades podem ser consideradas como reflexo do padrão histórico de administração pública adotada no Brasil.

Nesta mesma visão, Bastos (2015, p. 188) ao realizar a pesquisa na região norte do Brasil sobre o processo de gestão deste Plano, afirma que:

No contexto das práticas institucionais, pode-se constatar a frequência de alternância de coordenadores, membros do Fórum, o que num processo inicial da implementação pode indicar o uso da máquina administrativa como recurso político eleitoral, na malversação dos recursos, nos mecanismos casuístico com o planejamento das ações, nas parcerias firmadas entre os órgãos públicos para prestação de serviços.

Entendemos que este fator pode prejudicar a gestão geral do Programa, uma vez que tais mudanças podem "quebrar" o ritmo de trabalho da gestão em termos gerais, pois a cada mudança, são necessárias adaptações, inserções e conhecimento do trabalho já iniciado por outra gestão. Isto pode ser considerado como uma das fragilidades no processo de gestão do PARFOR na UFOPA.

Em entrevista com o Coordenador Local no município de Monte Alegre, a respeito de sua indicação para esta função, o mesmo relatou que:

Para ser coordenador do PARFOR, exige-se que tenha experiência ou na educação básica ou no nível superior, pelo menos um ano no nível superior ou três anos na educação básica e, como eu atendi esses prérequisitos, fui indicado e aceito pela reitoria da Universidade. Eu sou administrador, por isso fui escolhido para ser o coordenador do PARFOR. Eu estou atuando desde janeiro de 2011, quando eu entrei na UFOPA através do concurso público... Sou funcionário efetivo da UFOPA (ENTREVISTAS, Coordenador Local).

Percebemos que o Coordenador Local atende aos requisitos determinados no Manual Operativo do Plano, este determina no item 12.4, que trata dos requisitos mínimos obrigatórios para a concessão de bolsas aos coordenadores do PARFOR, que os mesmos devem:

a) comprovar ser servidor do quadro efetivo da instituição de ensino superior ou da secretaria estadual ou municipal de educação ou de órgão equivalente;

b) ter sua indicação aprovada pela Pró-reitoria da IES ou órgão equivalente;

c) quando tratar-se de servidor das secretarias estaduais ou municipais de educação ter sua indicação aprovada pelo representante máximo das respectivas Secretarias ou órgão equivalente;

d) comprovar formação em nível superior;

e) comprovar experiência de 3(três) anos no magistério na educação básica ou 1 (um) ano no magistério no ensino superior;

f) assinar termo de compromisso declarando ter disponibilidade para acompanhar as turmas especiais do PARFOR PRESENCIAL no município para o qual foi indicado. 
Diante do processo de gestão deste Plano, o qual foi planejado para funcionar a partir de um Regime de Colaboração entre os entes federados, o Coordenador Local relatou que a gestão municipal tem contribuído significativamente com a gestão do PARFOR no município de Monte Alegre.

No município de Monte Alegre, a questão da implantação do PARFOR foi bem sucedida, até porque nós sempre encontramos parceria, na Secretaria de Educação e na Prefeitura. A UFOPA sempre teve essas portas abertas para conduzir o PARFOR. Por enquanto, a UFOPA aqui em Monte Alegre só trabalha com o PARFOR. E, na medida do possivel, com a colaboração, tanto do espaço físico como de pessoal da escola que nós atuamos que sempre foi a escola Orlando Costa, uma escola nova. A gestão municipal sempre nos auxiliou na questão de aula de campo, também sempre tivemos apoio, de uma forma geral, a parceria e a colaboração, sempre funcionaram bem em Monte Alegre. A parceria entre a Universidade e o município sempre foi frequente e efetiva (ENTREVISTAS, Coordenador local).

Diante do processo de implantação do PARFOR nesse município, a partir do relato do Coordenador Local, percebemos a colaboração efetiva do governo municipal através da Secretaria de Educação e da Prefeitura. Entendemos que esse modelo de gestão, baseado em princípios democráticos e em constantes interações, facilita sua execução, à qual a colaboração e a participação, apresentam-se como critérios para o sucesso deste processo, cujo objetivo principal é a construção (coletiva) dos objetivos que a instituição pretende alcançar.

Cury (2007, p. 12) afirma que a gestão democrática é “... por injunção da nossa Constituição (BRASIL, 1988, art. 37): transparência e impessoalidade, autonomia e participação, liderança e trabalho coletivo, representatividade e competência".

Dessa forma, percebemos que tais princípios são necessários e imprescindíveis para que as deliberações, assim como os problemas sejam partilhados e solucionados de forma coletiva, para que as metas e os objetivos propostos sejam alcançados.

Em relação à Coordenação Geral do PARFOR, o Coordenador Local reafirmou a problemática relativa ao alto índice de rotatividade de coordenadores gerais e fez uma avaliação do trabalho desenvolvido por cada gestão:

Em apenas um pouco mais de cinco anos, contamos com seis coordenadores institucionais do PARFOR, a avaliação que faço de todos eles, é que nós observamos que há uma dinâmica muito boa, a vontade de que a região avance na questão educacional. Todos os coordenadores demonstraram lutar por melhorias na educação, não só em Santarém, mas em todos os municípios, tanto em Monte Alegre, como nos demais, sempre tivemos o apoio necessário. Assim, sempre que nós precisamos dos coordenadores institucionais eles resolveram todas as questões com a maior vontade e urgência possivel(ENTREVISTAS, Coordenador local).

Da mesma forma, o secretário Municipal de Educação do Município de Monte Alegre demonstrou satisfação com as gestões anteriores e com a atual gestão do PARFOR na UFOPA, tanto referente ao Coordenador Geral quanto ao Coordenador Local: 
Nossa relação com a Coordenação do PARFOR, tanto aqui em Monte Alegre, como com os Coordenadores Gerais em Santarém, sempre foi muito boa, sempre nos recebem quando solicitamos alguma reinvindicação e sempre nos apoiam nas decisões que visavam atender aos pedidos dos professores que estudam aqui no PARFOR. Já realizamos várias reuniões e sempre estão disponíveis. Acho isso muito bom porque facilita na resolução de alguns entraves. Então, posso considerar que a gestão do PARFOR referente ao campus de Monte Alegre é muito boa. Nossa relação é muito boa (ENTREVISTAS, Secretário Municipal).

A fala do secretário Municipal de Educação deixa transparecer a satisfação com a gestão do PARFOR neste município, pois o mesmo explicita que sempre manteve uma relação de cordialidade com os coordenadores e que os mesmos sempre se apresentavam disponíveis para diálogos e resolução de problemas.

Entendemos que a acessibilidade e contato efetivo entre a gestão municipal e gestão do PARFOR (Geral e Local) são fatores que influenciam diretamente para que a gestão do programa ocorra de forma harmoniosa e satisfatória, pois eventuais problemas serão inevitáveis. No entanto, a gestão democrática, também caracterizada como gestão compartilhada, favorecerá à resolução dos entraves.

Em suma, diante dos relatos dos entrevistados, percebemos que a gestão, no que diz respeito à participação/interação entre os sujeitos envolvidos na execução do PARFOR/UFOPA sempre ocorreu de forma harmoniosa e efetiva.

\subsection{Características do processo de implementação.}

Diante da complexidade e do dinamismo que o processo de implementação do PARFOR é organizado e diante de tantas responsabilidades atribuídas às IES e aos municípios, Bastos (2015, p. 188) compreende que:

As medidas desenvolvidas não têm sido eficazes e nem eficientes no sentido de contribuir para a montagem de um aparato institucional que contemple de forma explícita as regras do regime de colaboração entre as instituições estaduais, municipais e federais. Nesse caso, as Instituições Superiores de Ensino e as Secretarias de Educação ou equivalentes não são dotadas de infraestrutura condizente com as necessidades e as responsabilidades requeridas pelo Plano de Formação de Professores.

Em relação à execução/implementação do Plano e à participação da UFOPA neste processo, a Coordenadora Geral do PARFOR/UFOPA relatou que: 
Nós temos o fórum estadual do PARFOR, que é o fórum mais atuante no Brasil, ele tem uma periodicidade de reuniões, todo mês tem a reunião. Tem a reunião do Comitê interinstitucional em que todos os coordenadores das IES que fazem parte, no caso a UFOPA, UFPA, UEPA, IFPA e a UFRA e mais o diretor do Centro de Informação do Estado do Pará, que é o presidente do Fórum. Nós nos reunimos para que sejam deliberados todos os questionamentos que chegam ao fórum, denúncias de que professor fez a inscrição na Plataforma, mas por conta de questões políticas locais, ele não foi validado, denúncias da IESP não estarem contribuindo, não estarem fazendo a sua parte, porque lá no Manual Operativo está bem clara, qual parte que ele tem que fazer para a execução do programa, então assim, todos esses mecanismos no fórum são usados para uma execução de qualidade, por isso, a importância do Manual Operativo, que delibera sobre essas questões e a importância da realização dos fóruns estaduais (ENTREVISTAS, Coordenadora geral).

A entrevistada deixa explícita em sua fala que conhece a realidade do Fórum do Estado do Pará e que a realização dos mesmos é imprescindível para que questões de caráter prático/operacional, de gestão e execução, sejam ponderadas e solucionadas.

Entendemos que o Fórum é uma ferramenta de fundamental importância diante do processo de implementação do PARFOR, pois é o momento em que os diversos sujeitos envolvidos em sua execução se reúnem para debater os mais variados assuntos sobre questões de caráter administrativo e funcional visando a sanar problemas através do compartilhamento de realidades distintas.

Esse momento dialógico torna-se essencial para o sucesso deste processo, pois nesses momentos de discussão e interação são definidos os grupo de trabalho, assim, é possível percebermos também a responsabilidade política e operativa dos diferentes sujeitos envolvidos no processo na intenção de atender o público alvo, no caso, os professores da rede pública da educação básica.

De acordo com o Manual Operativo do PARFOR, a principal finalidade do Fórum é acompanhar sua execução e promover a revisão dos Planos Estratégicos elaborados pelas secretarias estaduais e municipais de educação, visando à análise e aprovação do quadro de oferta de cursos e vagas, conforme a demanda das redes de ensino.

Ainda sobre a finalidade dos Fóruns e a atuação do Fórum no estado do Pará, a Coordenadora Geral explicou que:

No Pará nós temos um Fórum que funciona, o programa está apresentando resultados, foi uma das questões que eu estive em Brasília dia 13 de maio, juntamente com as outras instituições participantes deste Fórum para uma reunião com a Professora Isabel Pessoa. Foi uma agenda que ela nos colocou disponível, então, foi uma chamada às instituições, e nós fomo. E é exatamente isso, esse diálogo que existe entre as instituições através do Fórum, então todos os assuntos são remetidos ao Fórum, para o que ele delibere, ou seja, decisões não são tomadas individualmente pelas instituições (ENTREVISTAS, Coordenadora geral). 
A compreensão da importância da realização dos Fóruns no estado do Pará fica evidente no relato da Coordenadora Geral, em que o diálogo é essencial diante da tomada de decisões.

Corroborando com a realidade apresentada pela Coordenadora Geral, sobre a atuação dos segmentos que compõem os Fóruns do PARFOR no estado do Pará, Bastos (2015, p. 190), reafirma que:

Verificou-se, assim, que houve a busca de vivenciar o aprendizado do tripartismo através da implementação do Parfor, conforme preconizava as normas nacionais acerca dos princípios da descentralização, participação e do estabelecimento das parcerias.

Fica evidente, portanto, que, assim como as demais IPES do estado do Pará, a UFOPA, através de sua coordenação geral, tem participado ativamente das reuniões dos Fóruns realizados neste período. A Coordenadora Geral enfatizou que:

A nossa universidade está sempre participando dos Fóruns... eu me inscrevi em todos os Fóruns, participando, dialogando, e mesmo não podendo oferecer tudo, a nossa universidade, no Fórum, ficou conhecida como uma universidade estratégica no Oeste do Pará, na formação dos professores. Pois nós tivemos mais de 900 alunos se formando até agora $e$ isso, consequentemente, vai refletir na sala de aula, e é claro na qualidade da educação (ENTREVISTAS, Coordenadora geral).

Diante desses dados quantitativos, percebemos a área de abrangência desta política e a expectativa da coordenadora em relação aos resultados que espera que reflita na práxis pedagógica docente para que ocorra a melhoria na qualidade do ensino nos municípios em que esses professores atuam. Em relação ao regime de colaboração adotado para a implementação dessa política, a Coordenadora Geral do PARFOR/UFOPA compreende que:

Nós temos essa percepção de que esse Regime de Colaboração na criação do programa, em que as três instâncias participam: a federal, municipal e estadual, elas deveriam estar interligadas mesmo, para que o programa acontecesse na sua plenitude, então o Manual Operativo do PARFOR ele traz todas as demandas de cada instância, o que compete a cada a IES, no caso à UFOPA, o que compete ao Estado, e o que compete às prefeituras, então está muito bem delineado (ENTREVISTAS, Coordenadora geral).

Portanto, os entes federados possuem funções que visam a estabelecer negociações e favorecer o bom desempenho do plano, dentre essas negociações existentes insere-se uma exigência da CAPES de que o Polo do município disponha de um laboratório de informática e uma sala disponível para colocar os livros.

No entanto, o Coordenador Local, ao ser questionado sobre os possíveis problemas existentes diante de sua implementação nesse município, afirmou que: 
O que nós temos de problemas refere-se à questão da internet, tanto para os servidores quanto para os alunos realizarem suas pesquisas. A internet sempre deixou a desejar, apesar de desde o início a gente ter internet, mas às vezes o sinal aqui em Monte Alegre é um pouco precário. Outro problema refere-se ao material didático, apesar de todos os alunos receberem uma apostila por disciplina, mas a falta de uma biblioteca para pesquisa, para que o aluno pudesse pesquisar além da apostila. Dentro dos cursos isto também é considerado um problema grave (ENTREVISTAS, Coordenador Local).

Assim, fica evidente que nem todos os acordos estabelecidos são cumpridos pelos entes federados, apesar de em fala anterior o Coordenador Local, defender que a implantação do PARFOR/UFOPA no município de Monte Alegre tenha sido bem sucedida com a disponibilização do espaço físico e diálogo constante; as questões referentes à falta de biblioteca e à precariedade quanto ao acesso à internet não foram correspondidas. No entanto, os coordenadores advogaram que este problema independe de ações desenvolvidas apenas pelo município.

A Coordenadora Geral afirmou que diante de alguns problemas, como este, a Universidade tem realizado esforços para mudar esta realidade:

Nós temos diversos desafios, pedagogicamente, nós temos o desafio de melhorar a qualidade do material utilizado pelos professores, para isso nós estamos trabalhando, e uma sugestão da nossa reitoria foi que agora nesta etapa, fizéssemos um DVD, para os professores-alunos, e esse material que a gente vem lutando desde que eu assumi, para que seja de qualidade, que realmente atenda a necessidade e transformação do PARFOR. Nós estamos trabalhando para que haja a implantação das bibliotecas nos municípios de Monte Alegre, Alenquer, Itaituba e Juruti... Alguns livros já foram comprados para o município de Juruti. Esse material que irá para o município de Juruti está em torno de 1.800 a 2.000 livros, que foram adquiridos com recursos da Pró-Reitoria de Ensino, uma vez que os recursos que vêm para o PARFOR, não permitem que nós possamos comprar material permanente, e livro é considerado material permanente (ENTREVISTAS, Coordenadora geral).

Evidenciamos que os problemas relacionados à falta de biblioteca, não é uma realidade apenas do município de Monte Alegre, mas que, de acordo com o relato da Coordenação Geral, é um problema que a Universidade pretende sanar de forma gradativa.

De forma geral, diante do processo de implantação do PARFOR/UFOPA no município de Monte Alegre e a participação e apoio da gestão municipal neste processo, a Coordenadora Geral expressou que: 
O município de Monte Alegre, foi um campus, um polo, que desde o início esteve sempre pronto a receber a universidade, todo momento que houve a configuração de implantação de Universidade em Monte Alegre, houve um diálogo com o poder decisivo local. Então, nós sempre estivemos acesso a todas as questões, para disponibilizarem as melhores escolas da época. O coordenador local é uma pessoa muito atuante no município, porque já teve uma experiência na educação básica, já tinha uma noção. Existe uma articulação política muito forte com o município, secretário de educação, com o prefeito na época, e ele mantém essa articulação até hoje. Então, isso facilita o diálogo, além do mais, em Monte Alegre os alunos são muito atuantes, talvez mais atuantes se comparados aos dos demais polos...os alunos de Monte Alegre estão bastante motivados em buscar a melhoria, a qualidade para a educação, eles estão sendo pessoas bastante atuantes, e que sempre verificam o que são os direitos e deveres deles (ENTREVISTAS, Coordenadora geral).

Da mesma forma, o secretário municipal de educação ao ser questionado sobre o processo de implementação do PARFOR/UFOPA no município de Monte Alegre afirmou que:

A prefeitura através da SEMED deu total apoio e total liberdade para os docentes participarem, inclusive dando o tempo, encurtando inclusive o calendário letivo para que eles pudessem estudar nos meses de janeiro e fevereiro, só voltando às atividades, só iniciando o ano letivo, após o término de cada módulo e isso já é um apoio muito grande, e também disponibilizando a estrutura física para que pudessem funcionar as turmas, então, a prefeitura cedeu a estrutura física e de certa forma um apoio logístico muito grande e dando total liberdade para que os docentes pudessem participar, nesse período intervalar e também quando se faz necessário interromperem as atividades nas escolas para virem desempenhar alguma atividade ou trabalho durante o ano letivo (ENTREVISTAS, Secretário municipal).

A parceria firmada entre Universidade e gestão municipal fica evidente na fala do secretário de educação, no entanto há um problema relativo ao não cumprimento do calendário letivo em detrimento da liberação dos professores para participarem das atividades do PARFOR. Entendemos, portanto que, se por um lado o Estado oferece condições para que o professor tenha formação adequada, por outro lado, a forma como esta política é conduzida prejudica o processo de ensino aprendizagem dos alunos, uma vez que os mesmos são penalizados com o encurtamento do calendário letivo e, consequentemente, com a supressão de algumas atividades planejadas para esses dias em que as aulas não ocorrem.

Ainda se tratando da problemática referente ao não cumprimento do calendário letivo, o Coordenador Local explicou que sua relação com a secretaria de educação nem sempre aconteceu com a mesma cordialidade apontada pelo secretário de educação, no entanto os problemas sempre são resolvidos de forma dialógica e passivamente. 
As secretarias de educação questionam muito esses períodos em que o PARFOR, devido à necessidade, precisa avançar além das férias escolares, de janeiro ele entra em fevereiro, e as secretarias tem que fazer um ajuste nos períodos de abril e outubro. Somos muito questionados pela secretaria de educação, porque os professores tem que sair, os alunos ficam sem aula, ou tem que conseguir outro professor, assim, essas problemáticas, vão acontecendo, e nós vamos resolvendo junto com a secretaria de educação, mas são problemas que vão acontecendo que é difícil de chegar a um denominador comum, porque atende aos professores, mas também tem o calendário escolar, digo o calendário letivo anual que tem que ser atendido (ENTREVISTAS, Coordenador local).

Levando em consideração o atual modelo de configuração em que essa política de formação docente foi planejada, uma vez que os profissionais contemplados por este Programa estão em pleno exercício de sua profissão e sua formação acontece nos períodos de recesso e férias, Mészáros (2008, p. 12) posiciona-se contrário a este modelo de formação e defende que devem existir

práticas educacionais que permitam aos educadores e alunos trabalharem as mudanças necessárias para a construção de uma sociedade na qual o capital não explore mais o tempo de lazer, pois as classes dominantes impõem uma educação para o trabalho alienante, com o objetivo de manter o homem dominado.

O determinismo neoliberal é evidentemente criticado por Mészáros, pois o fato dos professores terem que estudar em seu período de férias e recesso, estendendo-se ainda ao período letivo gera problemas/prejuízos à educação básica local e ainda um desgaste físico e emocional nos próprios professores que após este período exaustivo já tem que voltar às atividades pedagógicas sem seu merecido descanso.

\subsection{Percepções e impressões sobre os resultados alcançados.}

Os resultados alcançados por meio desta política e analisados neste estudo referemse às informações expressas a partir dos documentos e do site oficial do PARFOR, dos relatórios da CAPES e das percepções dos sujeitos pesquisados em relação ao quantitativo de professores-alunos formados/capacitados através do PARFOR/UFOPA no município de Monte Alegre, assim como sua área de abrangência.

A análise foi realizada com as turmas que ingressaram a partir do $2^{\circ}$ semestre do ano de 2010 e que concluíram sua graduação até o ano de 2015 no município de Monte Alegre/Pará. Para esta análise levamos em consideração o número de vagas ofertadas por curso, o número de inscrições solicitadas, o número de inscrições validadas pela secretaria de educação, o número de matrículas efetivadas, o número de desistentes/desvinculados e o número de concluintes.

Para o funcionamento do PARFOR/UFOPA no município de Monte Alegre-PA, foram ofertadas 05 (cinco) turmas com os cursos de: 1) Licenciatura em Pedagogia e as Licenciaturas Integradas em: 2) Biologia/Química, 3) Letras-Português/Inglês; 4) 
Matemática/Física; e 5) História/Geografia. Para cada turma foram ofertadas 50 (cinquenta) vagas, somando um total de 250 (duzentos e cinquenta) vagas.

É importante ressaltarmos que apenas a Universidade Federal do Oeste do Pará UFOPA implantou turmas nessa modalidade de Licenciaturas Integradas, nos demais estados do país, as IES implantaram apenas cursos específicos em uma única área de formação, ou seja, cursos sem integração de áreas distintas ou afins ${ }^{8}$.

Ao ser questionada sobre este fato incomum, a Coordenadora Geral do PARFOR/UFOPA respondeu que:

Já havia todo um condicionamento para a questão relativa à interdisciplinaridade. Então, esses cursos Integrados trariam essa interdisciplinaridade e foram pensados a partir desta concepção. E aquelas áreas poderiam ser aproximadas, elas ficaram como Licenciaturas Integradas. No entanto, o curso de Geografia, por exemplo, está separado no regular e, possivelmente, será separado também no PARFOR (ENTREVISTAS, Coordenadora geral).

Depois que a Universidade implantou as Licenciaturas Integradas, geraram-se inúmeras discussões a respeito da atuação profissional desses alunos que estariam se formando/habilitando para atuarem em duas áreas distintas. Inúmeros problemas surgiram ao longo da sua formação, alguns relacionados ao estágio que deveriam desenvolver e outros relacionados à questão do tempo de formação em duas áreas distintas (carga horária), e ainda, à certificação, pois até o momento ainda não se tinha aprovação do MEC para a expedição da certificação de cursos com essas características. Somados a estes, a dúvida quanto ao egresso poder participar de concurso público cuja exigência constante do Edital seja relativa a um curso específico.

Dessa forma, estes e outros fatores foram relevantes para que a Universidade modificasse esta proposta, e gradativamente, uma nova concepção foi implantada visando a separar os cursos nessa modalidade. No entanto, as primeiras turmas concluíram seus cursos da forma como foram organizados inicialmente.

Este, talvez, seja um problema que trará reflexos ao longo da atuação profissional dos professores que participaram desta formação, tendo em vista que algumas questões de ordem normativa e pedagógica ainda precisam de solução. O próprio sistema eletrônico do MEC, o Educacenso, só permite a inserção de uma área de formação docente para cada profissional.

Quanto às vagas ofertadas, número de pré-inscrições, inscrições validadas, matrículas efetivadas, alunos em processo de conclusão e o número de concluintes por curso e por turma na UFOPA, podemos observar esses dados na Tabela 02: 
Tabela 02. Resultados do PARFOR/UFOPA 2010/2015 - Monte Alegre/Pará.

\begin{tabular}{|c|c|c|c|c|c|c|c|}
\hline Curso & 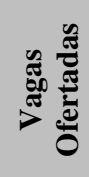 & 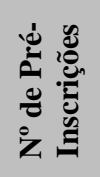 & 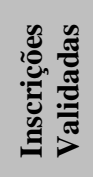 & 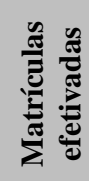 & 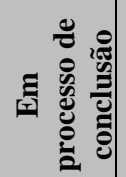 & 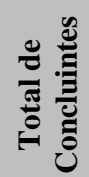 & $\%$ \\
\hline Lic. em Pedagogia & 50 & 57 & 49 & 39 & - & 32 & 82 \\
\hline Lic. Int. em Biologia e Química & 50 & 56 & 43 & 38 & 03 & 30 & 79 \\
\hline Lic. Int. em História e Geografia & 50 & 65 & 63 & 42 & 06 & 32 & 76 \\
\hline Lic. Int. em Matemática e Física & 50 & 57 & 51 & 45 & 05 & 36 & 82 \\
\hline Lic. Int. em Letras - Português e Inglês & 50 & 49 & 43 & 35 & 05 & 24 & 69 \\
\hline Total & 250 & 284 & 249 & 199 & 19 & 170 & 85,4 \\
\hline
\end{tabular}

Fonte: Elaborada pelos autores, a partir de dados fornecidos pela Secretaria de Educação (Técnico do PARFOR) e pela Coordenação Local do PARFOR/UFOPA, Campus de Monte Alegre/Pará - 2015.

A Tabela 02 demonstra que houve 284 professores/alunos pré-inscritos, 249 dessas pré-inscrições foram validadas pela Secretaria Municipal de Educação, 199 professores/alunos realizaram suas inscrições junto à Universidade e desse quantitativo, 170 professores-alunos conseguiram concluir sua formação com êxito, o que representa em média $85,4 \%$ de concluintes.

Existem ainda, os casos de desistência e/ou desvinculação, que representaram apenas o quantitativo de 10 (dez) professores/alunos neste município, em média 5\%. No entanto, não tivemos acesso a este quantitativo por curso. Vale a pena observarmos que ainda havia 19 (dezenove) professores/alunos em processo de conclusão, conforme a Tabela 03.

Tabela 03. Acadêmicos em processo de conclusão: PARFOR/UFOPA 2010/2015 Monte Alegre/Pará.

\begin{tabular}{l|c}
\hline \multicolumn{1}{c|}{ Turma/Curso } & $\begin{array}{c}\text { Quantidade de acadêmicos por } \\
\text { turma em processo de conclusão }\end{array}$ \\
\hline Licenciatura Integrada em Letras Português/Inglês & 05 \\
\hline Licenciatura Integrada em Biologia e Química & 03 \\
\hline Licenciatura Integrada em Matemática e Física & 05 \\
\hline Licenciatura Integrada em História e Geografia & 06 \\
\hline Total & $\mathbf{1 9}$ \\
\hline
\end{tabular}

Fonte: Elaborada pelos autores a partir de dados fornecidos pela Coordenação Local do PARFOR/UFOPA, Campus de Monte Alegre/Pará - 2015.

Se somarmos os 170 (cento e setenta) concluintes com os 19 (dezenove) que ainda estão em processo de conclusão e levarmos em consideração que todos conseguirão aprovação, o total de concluintes representará $95 \%$.

Diante desses resultados ressaltamos as concepções expressas por Barbalho (2007, p. 80), a respeito da expansão do ensino superior a partir da implementação de políticas públicas, como é o caso do PARFOR: "As políticas de expansão do ensino superior, traduzidas na criação de vagas, por meio de programas e projetos, na criação de diferentes tipos de instituições e de cursos, têm promovido a ampliação do setor". 
Dessa forma, podemos inferir que a área de abrangência e o percentual de concluintes podem ser avaliados de forma positiva no município de Monte Alegre.

No entanto, entendemos que esta política de formação docente se insere no contexto em que o governo tenta corrigir os erros do passado a partir de políticas compensatórias, pois apenas parte da população sem formação acadêmica (no caso os professores) será contemplada. Se por um lado o governo não pode melhorar o salário dos professores, por outro lado, promove políticas que proporcionem formação acadêmica, para que assim possam melhorar seus proventos.

Pois a mesma oferece uma formação aligeirada, de qualidade duvidosa, tendo em vista a situação de sobrecarga de trabalho do professor/aluno, sendo possível percebermos que o governo evidencia a preocupação apenas com os números a serem divulgados ao final da formação e não com a qualidade dos mesmos. É o que Frigotto (2010) chama de "pensamento econômico neoclássico", em que o ideário de igualdade econômica e social torna-se possível a partir de investimentos no capital humano, ou seja, quanto mais professores formados/capacitados existirem no Brasil, maiores serão os investimentos em educação por parte dos organismos internacionais e maiores serão os lucros advindos deste setor.

Neste sentido, percebemos a teoria do desenvolvimento e a teoria da educação evidenciadas por Frigotto (2010, p. 26):

A teoria do desenvolvimento concebe a educação como produtora de capacidade de trabalho, potenciadora de trabalho e, por extensão, potenciadora da renda, um capital (social e individual), um fator do desenvolvimento econômico e social... teoria da educação - a ação pedagógica, a prática educativa escolar reduzem-se a uma questão teórica, a uma tecnologia educacional cuja função precípua é ajustar requisitos educacionais a pré-requisitos de uma ocupação no mercado de trabalho de uma dada sociedade. Trata-se da perspectiva instrumentalista e funcional de educação.

Para demonstrar a situação funcional, o local, série e/ou ano em que atuam os professores do município de Monte Alegre que concluíram sua graduação por meio do PARFOR/UFOPA, elaboramos a Tabela 04: 
Tabela 04. Situação funcional, local e série de atuação dos egressos do PARFOR/UFOPA 2010-2015.

\begin{tabular}{|c|c|c|c|c|c|c|}
\hline \multirow[b]{2}{*}{ Área de formação } & \multicolumn{4}{|c|}{ Situação funcional } & \multicolumn{2}{|c|}{ Local de atuação } \\
\hline & 窇 & 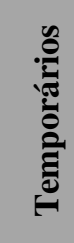 & 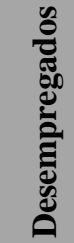 & 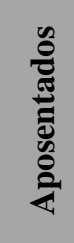 & 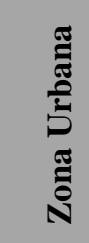 & 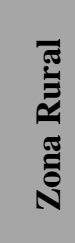 \\
\hline Lic. em Pedagogia & 28 & 01 & 07 & 02 & 08 & 21 \\
\hline $\begin{array}{c}\text { Lic. Int. em Biologia e } \\
\text { Química }\end{array}$ & 28 & 01 & 03 & - & 08 & 21 \\
\hline $\begin{array}{c}\text { Lic. Int. em História e } \\
\text { Geografia }\end{array}$ & 26 & 03 & 02 & 01 & 07 & 22 \\
\hline $\begin{array}{l}\text { Lic. Int. em Matemática e } \\
\text { Física }\end{array}$ & 23 & - & 15 & - & 05 & 18 \\
\hline $\begin{array}{l}\text { Lic. Int. em Letras - } \\
\text { Português e Inglês }\end{array}$ & 20 & 03 & 07 & - & 06 & 17 \\
\hline Total & 125 & 08 & 34 & 03 & 34 & 99 \\
\hline
\end{tabular}

Fonte: Elaborada pelos autores, a partir de dados fornecidos pela Secretaria de Educação (Técnico do PARFOR) e pela Coordenação Local do PARFOR/UFOPA, Campus de Monte Alegre/Pará - 2015.

Os dados apresentados na Tabela 04 revelam os resultados alcançados por essa política de formação docente neste município, no período de 2010-2015 em termos quantitativos.

Em média $74 \%$ dos professores contemplados/formados compõem o quadro de funcionários efetivos. Podemos considerar este como um fator positivo, tendo em vista que estes profissionais estão em pleno exercício de sua profissão. Menos de 5\% dos professores formados são funcionários temporários, menos de $2 \%$ já se aposentaram de suas atividades laborativas. No entanto, $20 \%$ dos professores formados estão desempregados, os quais faziam parte do quadro de funcionários temporários, e com o elevado índice de rotatividade na gestão deste município, muitos professores foram destratados durante o período de sua formação.

Outro dado importante, evidenciado na Tabela 04, diz respeito ao local de atuação desses profissionais, pois mais de $58 \%$ dos professores formados atuam na zona rural, em escolas do campo e regiões ribeirinhas. Ressaltamos que não tivemos acesso aos dados referentes ao local de atuação dos professores que foram destratados e dos aposentados, os quais somam um total de 37 (trinta e sete) professores contemplados/formados pelo PARFOR.

Ao fazer uma avaliação a respeito dos resultados quantitativos alcançados por esta política, o secretário municipal de educação a avaliou de forma positiva. 


\begin{abstract}
Nós avaliamos os resultados obtidos por este Plano de forma muito positiva, pois além de contemplar os professores em exercício da rede pública do ensino, é importante ressaltarmos que esses professores atuam em escolas da cidade, do campo e das regiões ribeirinhas do nosso município, ou seja, ele contemplou todos os professores, independente do seu local de atuação. É um plano muito abrangente e de fundamental importância para os nossos professores que sonhavam em cursar uma graduação, ainda mais através de uma Universidade Federal. Para todos nós é uma enorme satisfação fazer parte desse momento (ENTREVISTAS, Secretário municipal).
\end{abstract}

Assim, foi possível evidenciar que apenas $20 \%$ dos professores contemplados atuavam na zona urbana do município. Este fenômeno deve-se ao fato de muitos desses profissionais já se encontrarem em processo de aposentadoria, outros já possuíam nível superior, muitos estudaram em IES privadas, uma vez que anteriormente, as Universidades públicas (Federais/Estaduais) não possuíam Campus/Polo neste município e outros cursaram em outros municípios, porém, nesta mesma modalidade, em períodos de férias e recesso.

Em termos gerais, tendo em vista a área de abrangência do PARFOR em toda a região oeste paraense, a Coordenadora Geral relatou que:

Nós tivemos mais de 900 alunos se formando agora, e isso, consequentemente, vai refletir na sala de aula, é claro que nós trabalhamos em prol da educação, de uma educação de boa qualidade, os resultados vêm em longo prazo. No entanto, infelizmente para muitas pessoas a educação ainda é considerada uma despesa não um investimento. Nesse processo há credibilidade, a forma como este Plano foi divulgado, a Instituição e a qualidade através da qual o programa vem se apresentando no decorrer desses anos, também provocam influências. $O$ diálogo que a administração vem mantendo com as prefeituras, com as secretarias municipais de educação, $e$ principalmente, com a secretaria Estadual de Educação tem contribuído significativamente para esses resultados (ENTREVISTAS, Coordenadora geral).

Ao analisar a atuação da gestão municipal diante dos resultados alcançados, o Coordenador Local concluiu que a colaboração/participação da secretaria municipal de educação e do gestor municipal foi de suma importância para o sucesso desse processo.

O município sempre atendeu os professores do PARFOR, os nossos pedidos... sempre contávamos com a liberação dos professores, isso evitava motivos para que houvesse evasões. Pois aqui em Monte Alegre, esses indices foram bem menores que os dos outros municípios, porque nós ouvimos os relatos dos demais municípios, é que em muitos casos o 
gestor não tem toda essa sensibilidade. Assim, o professor é obrigado a escolher entre estudar e ter que trabalhar, ele vai optar por trabalhar não é mesmo? Acredito que a sensibilidade do município e o constante diálogo com a universidade fez com que o município pudesse alcançar o maior número de formandos (ENTREVISTAS, Coordenador local).

A partir do relato do Coordenador Local, o Regime de Colaboração regulamentado na legislação do PARFOR é evidenciado como efetivo e imprescindível para que os objetivos desse Plano pudessem se efetivar na prática. No entanto, aqui nesta análise, esses objetivos são evidenciados apenas em seu caráter quantitativo.

Os dados a seguir revelam algumas fragilidades diante do processo de implementação deste Plano no Município de Monte Alegre. Procuramos organizar esses dados considerando os docentes que possuíam $1^{a}$ Licenciatura, a área de formação e a área de atuação (série/ano e disciplina). Objetivando sintetizar todos esses dados, elaboramos a Tabela 05.

Tabela 05. Resultados Licenciaturas do PARFOR/UFOPA - Monte Alegre/ 2010-2015.

\begin{tabular}{|c|c|c|c|c|c|c|c|}
\hline Curso & שֶ气 & $\begin{array}{l}\text { Com 1a } \\
\text { Licenc. }\end{array}$ & $\begin{array}{c}\text { Atuação } \\
\text { de acordo } \\
\text { com a 1 } 1^{\mathrm{a}} \\
\text { Licenc. }\end{array}$ & $\begin{array}{c}\text { Atuação } \\
\text { diferente } \\
\text { da } 1^{\mathbf{a}} \\
\text { Licenc. }\end{array}$ & $\begin{array}{l}\text { Atuação de } \\
\text { acordo com } \\
\text { a } 2^{\mathrm{a}} \text { Licenc. } \\
\text { (PARFOR) }\end{array}$ & $\begin{array}{c}\text { Atuação } \\
\text { diferente da } \\
\mathbf{2}^{\mathbf{a}} \text { Licenc. } \\
\text { (PARFOR) }\end{array}$ & 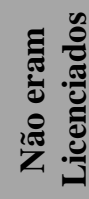 \\
\hline $\begin{array}{c}\text { Lic. em } \\
\text { Pedagogia }\end{array}$ & 38 & 07 & - & 07 & 29 & - & 31 \\
\hline $\begin{array}{c}\text { Lic. Int. em } \\
\text { Biologia e } \\
\text { Química }\end{array}$ & 32 & 22 & 04 & 06 & - & 32 & 10 \\
\hline $\begin{array}{c}\text { Lic. Int. em } \\
\text { História e } \\
\text { Geografia }\end{array}$ & 32 & 27 & 13 & 12 & 10 & 12 & 05 \\
\hline $\begin{array}{l}\text { Lic. Int. em } \\
\text { Matemática } \\
\text { e Física }\end{array}$ & 38 & 15 & 04 & 10 & 08 & 06 & 23 \\
\hline $\begin{array}{l}\text { Lic. Int. em } \\
\text { Letras - } \\
\text { Português e } \\
\text { Inglês }\end{array}$ & 30 & 17 & 04 & 13 & 12 & 05 & 13 \\
\hline Total & 170 & 88 & 25 & 48 & 59 & 55 & 82 \\
\hline
\end{tabular}

Fonte: Elaborada pelos autores, a partir de dados fornecidos pela Secretaria de Educação (Técnico do PARFOR) e pela Coordenação Local do PARFOR/UFOPA, Campus de Monte Alegre/Pará - 2015.

Diante desses dados, percebemos, que em média: 52\% dos professores que se formaram através do PARFOR/UFOPA nesse município já possuíam uma $1^{\mathrm{a}}$ Licenciatura e $48 \%$ não eram licenciados. No entanto, somente $35 \%$ se licenciaram em sua área de atuação, pois a maioria optou por fazer outra licenciatura, novamente distinta de seu campo de atuação.

Apenas 15\% atuavam em sua área de formação de acordo com sua $1^{a}$ licenciatura, $28 \%$ atuavam em áreas diferentes de sua $1^{\mathrm{a}}$ licenciatura, $35 \%$ estavam atuando na área de acordo com a $2^{\text {a }}$ licenciatura, a qual foi efetivada através do PARFOR, e 32,5\% ainda 
continuavam atuando em áreas diferentes de sua $2^{\mathrm{a}}$ licenciatura, apesar da $2^{\mathrm{a}}$ licenciatura objetivar corrigir essa problemática.

Esses dados demonstram uma preocupante fragilidade diante da implementação dessa política nesse município, pois de acordo com o Manual Operativo do PARFOR combinado com os dispositivos a partir do artigo 11, inciso II do Decreto n 6.755 de 29 de janeiro de 2009, seus objetivos estão bem explícitos:

I. Primeira Licenciatura para docentes ou tradutores intérpretes da Língua Brasileira de Sinais (LIBRAS) em exercício na rede pública da educação básica, que não tenham formação superior ou que mesmo tendo essa formação se disponham a realizar curso de licenciatura na etapa/disciplina em que está atuando em sala de aula;

II. Turmas de Segunda Licenciatura, destinadas para professores que estejam em exercício há pelo menos três anos na rede pública de educação básica e que atuam em área distinta da sua formação inicial, ou para profissionais que atuam como tradutor intérprete de Libras;

III. A terceira composição de turmas tem como objetivo a Formação Pedagógica para docentes graduados não licenciados que se encontram no exercício da docência ou que atuem como tradutor intérprete de Libras na rede pública da educação básica. (grifos nossos).

Assim, todos os professores que se formaram através desse Plano no período pesquisado, foram inscritos e inseridos na Plataforma Freire por meio da Secretaria Municipal de Educação na categoria "Primeira Licenciatura". Porém, como pudemos observar muitos já possuíam formação em nível superior e um número expressivo dos que já possuíam a $1^{\mathrm{a}}$ licenciatura diferente de sua área de atuação, optou por realizar a $2^{\mathrm{a}}$ licenciatura novamente em área diferente de sua atuação profissional. Isso significa que esses professores permanecem no contingente de professores que não possuem formação adequada à sua área de atuação profissional.

Diante desses problemas, evidenciamos a importância de cada ente federado no processo de implementação dessa política, em que cada um deve conhecer detalhadamente suas atribuições e buscar estratégias para cumpri-las.

Tendo em vista essas fragilidades, a partir de abril do ano de 2012, a Plataforma Freire passou por algumas mudanças. Novos módulos foram introduzidos e foram realizadas integrações com outros sistemas do MEC com o objetivo de torná-la mais eficiente nos processos de gestão e acompanhamento do Programa. Outras ocorreram nas Universidades, em que a forma de ingresso/matrícula dos professores-alunos se deu a partir da apresentação de uma Declaração expedida pela Secretaria Municipal de Educação, comprovando a área de atuação desses profissionais.

De acordo com o Relatório de Gestão da DEB Vol. 1 (2009-2014, p. 35), uma das mudanças ocorridas, e que podem evitar o problema de pré-inscrições e matrículas de forma irregular/inadequada, refere-se à Integração da Plataforma Freire com outros sistemas, como a "Integração com a base de dados do Educacenso - essa ação permitiu verificar se os solicitantes de pré-inscrições estão cadastrados nessa base de dados como docentes da rede pública de educação básica".

A respeito do processo de implementação do PARFOR Gatti, Barreto e André (2011, p. 256) entendem que: 
A análise da sua implementação reveste-se, por sua vez, de especial complexidade, não só pelo tamanho continental do país, como também pelo regime pluripartidário adotado e pela pluralidade de entes federados decorrente do regime federativo, que confere também aos municípios atribuições de entes federados.

Gatti, Barreto e André (2011), continuam suas inferências apontando que as formas de colaboração entre os entes federados têm sido determinadas fundamentalmente pela União. No entanto, não há clareza sobre como elas se articularão com as políticas formuladas pelos estados e pelos municípios, uma vez que o regime de colaboração não está plenamente estabelecido.

Talvez estes sejam os motivos pelos quais ainda persistem alguns problemas diante do seu processo de implementação e que, com certeza, refletirão em seus resultados finais, e consequentemente, na qualidade do ensino no país.

\section{Considerações finais}

A pesquisa permitiu verificar que a gestão do PARFOR na Universidade Federal do Oeste do Pará (UFOPA) foi caracterizada pelo alto índice de rotatividade na Coordenação Geral que, ao longo de cinco anos, contou com seis coordenações distintas, as quais se mantiveram em exercício por períodos inferiores a um ano ininterrupto. Entendemos que este fator gerou problemas à gestão geral do Programa, uma vez que tais mudanças "quebram" o ritmo de trabalho, sendo necessárias constantes adaptações, inserções e conhecimento do trabalho já iniciado por outra gestão.

Todavia, a gestão foi realizada de acordo com a regulamentação constante no Manual Operativo, o qual determina que a coordenação geral do Programa deva ser indicada pelo(a) representante legal da IES ou órgão equivalente e que deve atender a requisitos mínimos relacionados à formação acadêmica.

O processo de implantação do PARFOR na UFOPA foi alicerçado em princípios da legalidade e obedeceu a todos os trâmites legais para sua efetivação, desde a assinatura do Termo de Adesão ao Acordo de Cooperação Técnica à assinatura dos Termos de Cooperação Simplificado e Aditivo.

A partir das entrevistas, evidenciamos que a Coordenação Local e a Coordenação Geral compreendem que a gestão municipal cumpriu com suas atribuições de forma satisfatória. No entanto, em sua efetivação, houve problemas relacionados à falta de biblioteca e dificuldades quanto ao acesso à internet. Na concepção dos coordenadores tais problemas independem de ações isoladas da gestão municipal. No entanto, as precárias condições de acesso à internet e a falta de livros (biblioteca) para a realização de consultas e/ou pesquisas também fragilizam e afetam a qualidade da formação dos professores, pois a maioria é oriunda da zona rural do município, onde também não há disponibilidade desses serviços.

Outra fragilidade evidenciada refere-se ao fato de os professores terem que estudar em períodos além do que é previsto, comprometendo, além das férias e recesso, outras fases do período letivo. Esse fato gera problemas à educação básica local e desgaste físico e emocional nos professores-alunos que após este período exaustivo têm que voltar às atividades pedagógicas sem o necessário descanso.

Constitui problema também o fato de que apenas a UFOPA implantou turmas na modalidade de Licenciaturas Integradas, as demais IES ofertaram cursos específicos em 
uma única área de formação. Este, talvez, seja um problema que trará reflexos ao longo da atuação profissional dos professores que participaram desta formação, pois algumas questões de ordem normativa e pedagógica ainda precisam de solução, tendo em vista que o próprio sistema eletrônico do MEC, o Educacenso, permite a inserção de apenas uma área de formação docente para cada profissional. Somados a estes, persiste a dúvida quanto ao egresso poder participar de concurso público cuja exigência constante do Edital seja relativa a um curso específico.

Apesar dos problemas evidenciados, notamos que os Coordenadores (Geral e Local) desta Universidade conheciam e respeitavam os princípios definidos nos documentos que regulamentam o PARFOR diante do seu processo de implementação e que mantinham uma relação de cordialidade, respeito e reconhecimento diante de suas atribuições/funções entre si e com a gestão municipal.

Percebemos que as contradições e problemas inerentes ao processo de gestão e implementação do PARFOR, a nível nacional e local, em alguns momentos estavam associados à ausência de participação da categoria docente em seu processo de formulação e execução. Desde a sua gênese até a sua implantação e implementação são ínfimas as evidências que revelam a participação dos professores no que diz respeito à definição e à construção desta política de formação docente. Assim como não foi possível evidenciarmos relações da mesma com a prática desses profissionais diante das reais condições de trabalho no cotidiano escolar, o que por sua vez, a fragiliza e a torna motivo de muitas dúvidas e questionamentos quanto às expectativas relacionas às mudanças efetivas em sala de aula para a melhoria da qualidade do ensino. Desta forma, entendemos que a formação desses profissionais não se apresenta como garantia de que a educação terá qualidade em sua aplicação prática no cotidiano escolar.

Os resultados demonstram que, no município de Monte Alegre/PA, dos 284 professores/alunos pré-inscritos, 249 inscrições foram validadas pela Secretaria Municipal de Educação, 199 realizaram suas matrículas junto à Universidade e desse quantitativo, 10 desistiram e/ou foram desvinculados dos cursos, o que representa em média 5\% do total que efetivaram matrícula. 170 conseguiram concluir sua formação com êxito, o que representa, em média, $85,4 \%$ de concluintes. Ressalte-se que no momento de coleta dos dados ainda havia 19 (dezenove) professores/alunos em processo de conclusão.

Esta pesquisa nos possibilitou o conhecimento de que, em média, $74 \%$ dos professores contemplados/formados faziam parte do quadro de funcionários efetivos, menos de $5 \%$ eram funcionários temporários, menos de $2 \%$ já havia se aposentado e mais de $58 \%$ atuavam na zona rural, em escolas do campo e regiões ribeirinhas. E $20 \%$ dos professores formados estavam desempregados.

Percebemos que tanto a nível nacional, como local, ocorreram mudanças no processo de implementação do PARFOR, na intenção de minimizar e/ou solucionar os problemas e as dificuldades evidenciadas. Algumas dessas mudanças ocorreram no sistema eletrônico do próprio Plano (Plataforma Freire), através de sua vinculação com o sistema eletrônico do MEC (Educacenso). Outras ocorreram nas Universidades, em que a forma de ingresso/matrícula dos professores-alunos se deu a partir da apresentação de uma Declaração expedida pela Secretaria Municipal de Educação, comprovando a área de atuação do profissional, na intenção de evitar problemas como os evidenciados no município pesquisado.

É inegável a contribuição do PARFOR na formação de professores. Os números confirmam tratar-se da mais arrojada ação do MEC visando a melhorar a qualidade do ensino público no país, por meio da formação inicial e/ou continuada de professores. No 
entanto, para que haja significativa mudança na ação didático-pedagógica torna-se imprescindível que haja adequações nos processos de implementação e de gestão dessa política, para que os resultados não sejam apenas em termos quantitativos, mas, principalmente, em termos qualitativos e reflitam efetivamente na práxis pedagógica docente.

\section{Referências}

BARBALHO, Maria Goretti Cabral. A educação Superior: tendências e estratégias de expansão na América Latina e no Brasil. In:Antonio Cabral Neto et al. (Orgs.). Pontos e contrapontos da política educacional: Uma leitura contextualizada de iniciativas. Brasília: Liber Livro Editora, 2007.

BASTOS, Ana Fanny Benzi Oliveira. Análise da implementação do Plano Nacional de Formação de Professores da Educação Básica em Estados da Região Norte do Brasil. 2015. 210 f. Tese (Doutorado em Educação), Universidade Estadual de Campinas Unicamp, Campinas, 2015.

BRASIL. Lei $n^{\circ}$ 9.394, de 20 de dezembro de 1996. Estabelece as Diretrizes e Bases da Educação Nacional. Disponível em: <http://www.presidencia.gov.br/legislacao/>. Acesso em novembro de 2013.

BRASIL. Lei 12.085, de 5 de novembro de 2009. Dispõe sobre a criação da Universidade Federal do Oeste do Pará - UFOPA, por desmembramento da Universidade Federal do Pará - UFPA e da Universidade Federal Rural da Amazônia - UFRA, e dá outras providências. Disponível em: < http://www.planalto.gov.br/ccivil_03/_Ato20072010/2009/Lei/L12085.htm>. Acesso em março de 2012.

BRASIL. Ministério da Educação. Conselho Nacional de Educação. Decreto $n^{\circ} 6.755$, de 29 de Janeiro de 2009. Disponível em <http://www.planalto.gov.br/ccivil_03/_ato20072010/2009/Decreto/D6755.htm> Acesso em Novembro de 2013.

CAPES. Manual Operativo do Parfor. Disponível em: <http://www.capes.gov.br.> Acesso em 20 de março de 2014.

CAPES/DEB. Relatório de Gestão 2009-2014 / Volume I. Disponível em:

L<http://www.capes.gov.br/images/stories/download/bolsas/20150818_DEB-relatorio-degestao-vol-1-com-anexos.pdf $>$ Acesso em 04 de julho de 2015.

COLARES A.A.; COLARES M.L.I. S. As políticas Educacionais e a Formação de Professores. In: Débora Cristina Jeffrey, Luis Enrique Aguiar (Orgs.). Balanço da política educacional brasileira (1999-2009): ações e programas. - 1. ed. - Campinas, SP: Mercado de Letras, 2013.

CURY, Carlos Roberto Jamil. A gestão democrática na escola e o direito à educação. Revista Brasileira de Política e Administração da Educação. v.23, n. ${ }^{\circ}$ 3, p. 483-495, set/dez. 2007. 
DI GIORGI, Cristiano Amaral Garboggini et. al. Necessidades formativas de professores de redes municipais: contribuições para a formação de professores crítico-reflexivos. São Paulo: Cultura Acadêmica, 2010.

DINIZ-PEREIRA, Júlio Emílio. A pesquisa dos educadores como estratégia para a construção de modelos críticos de formação docente. In: Júlio Emílio Diniz-Pereira e Kenneth M. Zeichner (Org.). A pesquisa na formação e no trabalho docente. 2. ed. - Belo Horizonte: Autêntica Editora, 2011.

ENTREVISTAS. Com coordenador local, coordenadora geral, secretário municipal.

FREITAS, H. C. L. A (nova) política de formação de professores: a prioridade postergada. Educação \& Sociedade, Campinas, v. 28, n. ${ }^{\circ}$ 100, Especial, p. 1203-1230, out. 2007.

FRIGOTTO, Gaudêncio. A produtividade da escola improdutiva: um (re)exame das relações entre educação e estrutura econômico-social capitalista. 9.ed. - São Paulo: Cortez, 2010.

GATTI, Bernadete Angelina e BARRETO, Elba Siqueira de Sá(Coord.). Professores do Brasil: impasses e desafios. Brasília: UNESCO, 2009.

GATTI, B. A.; BARRETO, E. de Sá; ANDRÉ, M. E. D. Políticas docentes no Brasil: um estado da arte. Brasília: UNESCO, 2011.

MAINARDES, J.; FERREIRA, M. S.; TELLO, C. Análise de políticas: fundamentos e principais debates teórico-metodológicos. In: BALL, S. J.; MAINARDES, J. (Org.)

Políticas educacionais: questões e dilemas. São Paulo: Cortez, 2011.

MÉSZÁROS, István. A educação para além do capital. [Tradução Isa Tavares]. - 2.ed. São Paulo: Boitempo, 2008.

SAVIANI. Dermeval. Política e educação no Brasil: o papel do Congresso Nacional na legislação do ensino. 6. ed.; I reimpressão - Campinas, SP: Autores Associados, 2008.

Notas

${ }^{1}$ Universidade Federal do Oeste do Pará - UFOPA.

2 Docente da Universidade Federal do Oeste do Pará - UFOPA.

3 Podemos destacar: DINIZ-PEREIRA (2011), FREITAS (2007), GATTI, BARRETO (2009), GATTI, BARRETO e ANDRÉ (2011), MAINARDES (2011), SAVIANI (2008) entre outros.

${ }^{4}$ Os sete municípios onde funcionam os polos do PARFOR através da UFOPA são: Santarém, Alenquer, Juruti, Oriximiná, Óbidos, Itaituba e Monte Alegre.

5 Sistema eletrônico criado em 2009 pelo Ministério da Educação, com a finalidade de realizar a gestão e acompanhamento do Plano Nacional de Formação dos Professores da Educação Básica - PARFOR. 
${ }^{6}$ Levantamento de dados educacionais realizado no Brasil pelo Ministério da Educação (MEC).

${ }^{7}$ A Legislação básica de referência do PARFOR compreende o Decreto no 6.094, de 24 de abril de 2007; o Decreto $\mathrm{n}^{\mathrm{o}}$ 6.755, de 29 de janeiro de 2009; a Portaria Normativa $\mathrm{n}^{\circ}$ 9, de 30 de junho de 2009 e a Portaria Normativa ${ }^{\circ} 883$, de 16 de setembro de 2009.

8 As informações a respeito de todos os cursos ofertados e em andamento encontram-se disponíveis em: http://www.capes.gov.br/educacao-basica/parfor. Acesso em: Julho de 2014.

Recebido: Abril/2016.

Aprovado: Junho/2017. 